Article

\title{
Low Temperature Synthesis of Nest-Like Microsphere with Exposed (001) Facets and Its Enhanced Photocatalytic Performance by $\mathrm{NaOH}$ Alkalization
}

\author{
Chentao Hou * ${ }^{\mathbb{D}}$, Jiaming Zhu and Qiaoqiao Song \\ College of Geology and Environment, Xi'an University of Science and Technology, Xi'an 710054, China; \\ XRD610@126.com (J.Z.); sqqxakjdx@163.com (Q.S.) \\ * Correspondence: houct@xust.edu.cn; Tel.: +86-029-8558-3188
}

Received: 31 December 2017; Accepted: 5 February 2018; Published: 8 February 2018

\begin{abstract}
In this study, we completed a simple low-temperature synthesis of nest-like titanium oxide $\left(\mathrm{TiO}_{2}\right)$ microspheres with exposed (001) facets. For the first time, the photocatalytic performance was enhanced by sodium hydroxide $(\mathrm{NaOH})$ alkalization. The characterization of as-synthesized $\mathrm{F}-\mathrm{TiO}_{2}$ and $\mathrm{OH}-\mathrm{TiO}_{2}$ were analyzed by field emission scanning electron microscopy, high-resolution transmission electron microscopy, $\mathrm{X}$-ray diffraction, fourier transform infrared spectroscopic analysis, ultraviolet-vis diffuse reflection spectra and Raman spectroscopy. The photocatalytic activity of the as-prepared catalyst was evaluated through the photocatalytic degradation of methylene blue (MB) and Rhodamine $\mathrm{B}(\mathrm{RhB})$ under simulated solar light. The results showed that modification using $\mathrm{NaOH}$ can lead to an increase in the percentage of (001) facets from $27.8 \%$ for $\mathrm{F}^{-\mathrm{TiO}_{2}}$ to $39.2 \%$ for $\mathrm{OH}-\mathrm{TiO}_{2} \cdot \mathrm{OH}-\mathrm{TiO}_{2}$ showed superior catalytic photoactivity toward $\mathrm{MB}$. The mechanism of $\mathrm{NaOH}$ on $\mathrm{TiO}_{2}$ is also discussed.
\end{abstract}

Keywords: $\mathrm{F}-\mathrm{TiO}_{2} ; \mathrm{OH}-\mathrm{TiO}_{2} ;(001) \mathrm{TiO}_{2} ;$ methylene blue; nest-like

\section{Introduction}

Since Fujishima discovered that titanium oxide $\left(\mathrm{TiO}_{2}\right)$ could split water in 1972 [1], $\mathrm{TiO}_{2}$ has been studied for its lack of toxicity, low cost and stability, which make it a promising photocatalyst for environmental remediation [2-4] and hydrogen evolving [5]. The decreasing order of the surface energies of anatase $\mathrm{TiO}_{2}$ has been found to be $0.90 \mathrm{~J} / \mathrm{m}^{2}$ for (001), $0.53 \mathrm{~J} / \mathrm{m}^{2}$ for (100) and $0.44 \mathrm{~J} / \mathrm{m}^{2}$ for (101) [6,7], so most anatase $\mathrm{TiO}_{2}$ has a low-energy (101) surface rather than high-energy $(001)$ facets [8-16]. The (001) surface of anatase $\mathrm{TiO}_{2}$ is much more reactive than the (101) surface $[17,18]$. Developing a technique to exposure the surface of (001) has proven to be a challenge.

In 2008, Yang et al. successfully prepared anatase $\mathrm{TiO}_{2}$ crystals with as much as $47 \%$ of the (001) facets being exposed using a surface fluorination method [19]. Since then, studies on (001) faceted anatase $\mathrm{TiO}_{2}$ have been completed [20-27]. However, most of the (001) faceted anatase $\mathrm{TiO}_{2}$ crystals were prepared at high temperature through calcination or hydrothermal techniques [20-27].

Akali-modification of catalysts have also been proven to be effective on enhancing the photo-activity in methane dehydroaromatization, cumene cracking and carbon monoxide (CO) oxidation [28-30]. For example, Han et al. [28] found that alkali could form more hydroxyl on gold $(\mathrm{Au})$ catalysts to enhance their catalytic activity. Alkali modified ZSM-5 zeolite also showed enhanced catalytic performance due to the formation of additional mesopores and the improvement of mass transfer and reaction kinetics [29,30]. The performance of sodium hydroxide $(\mathrm{NaOH})$-modified $\mathrm{Pt} / \mathrm{TiO}_{2}$ was enhanced with the oxidation of formaldehyde at room temperature [30]. This present study attempted to modify $\mathrm{TiO}_{2} / \mathrm{TiOF}_{2}$ by $\mathrm{NaOH}$ to enhance its catalytic performance. 
Furthermore, F-doped $\mathrm{TiO}_{2}$ is thought to have (001) facet exposure, and the fluoride ions remain well bound and stable on the surface of $\mathrm{F}-\mathrm{TiO}_{2}$ samples. Further study is required on the mechanism by which the $\mathrm{NaOH}$ modification occurs on $\mathrm{F}^{-\mathrm{TiO}_{2}}$, the morphology, (001) facet exposure, crystal properties, ultraviolet (UV)-vis adsorption properties, and the crystal defect changes of $\mathrm{F}_{-}-\mathrm{TiO}_{2}$ after $\mathrm{NaOH}$-modification. In this paper, a low-temperature synthesis method for $\mathrm{TiO}_{2}$ microspheres with exposed (001) facets is reported, and the photocatalytic performance was enhanced by $\mathrm{NaOH}$ alkalization (nest-like $\mathrm{OH}-\mathrm{TiO}_{2}$ ) for the first time. The morphology, (001) facet exposure, crystal properties, UV-vis adsorption properties, and crystal defects changes were studied. The photocatalytic performance of the as-prepared catalyst was tested using the photocatalytic degradation of methylene blue (MB) and Rhodamine $\mathrm{B}(\mathrm{RhB})$ under simulated solar light. The $\mathrm{NaOH}$ alkalized microspheres showed superior catalytic photoactivity towards $\mathrm{MB}$. The mechanism of $\mathrm{NaOH}$ toward $\mathrm{TiO}_{2}$ is also discussed.

\section{Results and Discussion}

\subsection{Structural Characterization}

Figure 1 shows the $\mathrm{X}$-ray diffraction (XRD) patterns of as-prepared $\mathrm{F}-\mathrm{TiO}_{2}$ and $\mathrm{OH}-\mathrm{TiO}_{2}$ samples. No apparent peaks of other phases were found, meaning that both samples were pure crystals. The XRD peak positions for both the samples at $2 \theta$ were $25.28^{\circ}, 37.80^{\circ}, 48.04^{\circ}, 53.89^{\circ}, 55.06^{\circ}, 62.68^{\circ}$, $70.31^{\circ}$ and $75.03^{\circ}$, which matches well with anatase $\mathrm{TiO}_{2}$ (JCPDS card No. 21-1272) and different from P25 (mixed crystals of anatase and rutile $\mathrm{TiO}_{2}$ ). The characteristic diffraction peak intensity of $\mathrm{F}^{-\mathrm{TiO}_{2}}$ is obviously stronger than that of $\mathrm{OH}-\mathrm{TiO}_{2}$, meaning that the crystallinity of the sample can be increased with fluorine ions, which aligns with the results of Xiang et al. [31]. After $\mathrm{NaOH}$ treatment, the crystal form of the catalyst changed, which aligns with the results of Hou Chentao et al. [32].

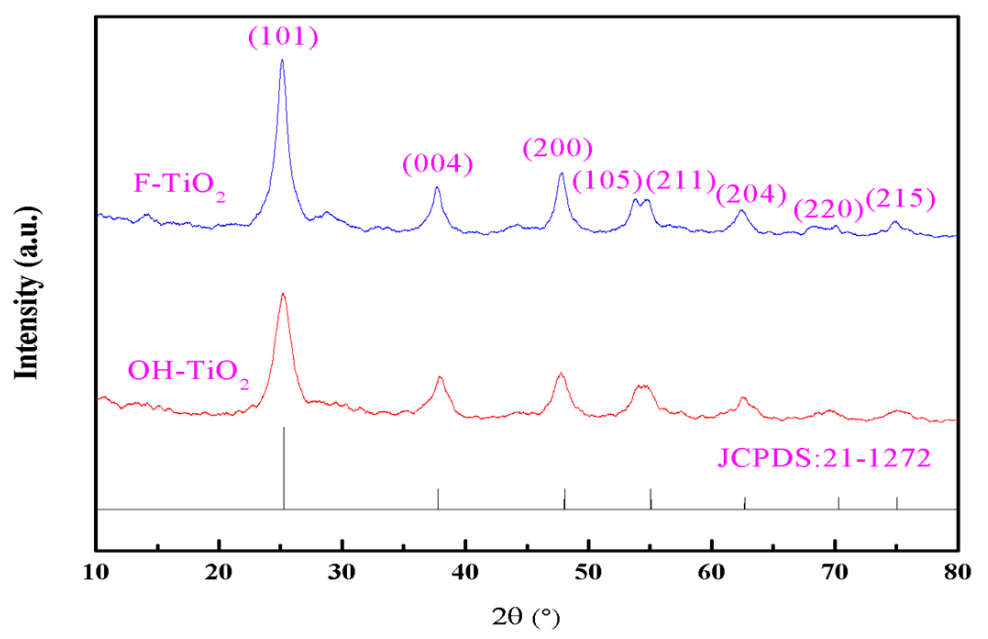

Figure 1. X-ray diffraction (XRD) patterns of as-prepared $\mathrm{F}-\mathrm{TiO}_{2}$ and $\mathrm{OH}-\mathrm{TiO}_{2}$ samples.

The morphology of the as-prepared samples was characterized by field emission scanning electron microscopy (FE-SEM), and high-resolution transmission electron microscopy (HRTEM) in Figure 2. The as-synthesized $\mathrm{F}-\mathrm{TiO}_{2}$ has a hollow microsphere shape with an average size of around 700-900 nm covered with compact particles of around $50 \mathrm{~nm}$ (Figure 2a). This shape may be explained by the Ostwald ripening process [33]. In the HRTEM (Figure $2 \mathrm{c}$ and, especially in Figure 2d), the spacing of the lattice fringe was $0.352 \mathrm{~nm}$ and $0.235 \mathrm{~nm}$, respectively, corresponding to the lattice distance of the (101) and (001) plane of anatase $\mathrm{TiO}_{2}[34,35]$. So the surfaces of the $\mathrm{F}-\mathrm{TiO}_{2}$ microspheres are covered with small (001) exposure crystals. From Figure $2 \mathrm{~b}$, after modification by $\mathrm{NaOH}$, the microspheres were destroyed and the compact particles became loose and hairy, developing a nest-like structure. 
As can be seen in Figure 2e,f, the nest-like structure also has the (001) surface exposed, permitting light-scattering inside the shell wall and enhancing absorption in light. We think the mechanics may be as follows. When the $\mathrm{NaOH}$ is added, the $\mathrm{F}$ ions will be exchanged by $\mathrm{OH}$ of $\mathrm{NaOH}$, the transformation takes place starting from the edges and corners of the $\mathrm{F}^{-\mathrm{TiO}_{2}}$ [36], which are of high surface energy. The transformation leads to the gradual formation of $\mathrm{OH}-\mathrm{TiO}_{2}$ with more (001) facets exposure and flatter $\mathrm{TiO}_{2}$ sheets. The transformation also makes the compact $\mathrm{F}-\mathrm{TiO}_{2}$ crystals looser and take on a nest-like shape. The nest-like structure increases the $\mathrm{OH}-\mathrm{TiO}_{2}$ surface area $\left(S_{\mathrm{BET}}\right)$ to $55 \mathrm{~m}^{2} / \mathrm{g}$, which is much larger than that of $\mathrm{F}-\mathrm{TiO}_{2}$ at $20 \mathrm{~m}^{2} / \mathrm{g}$.

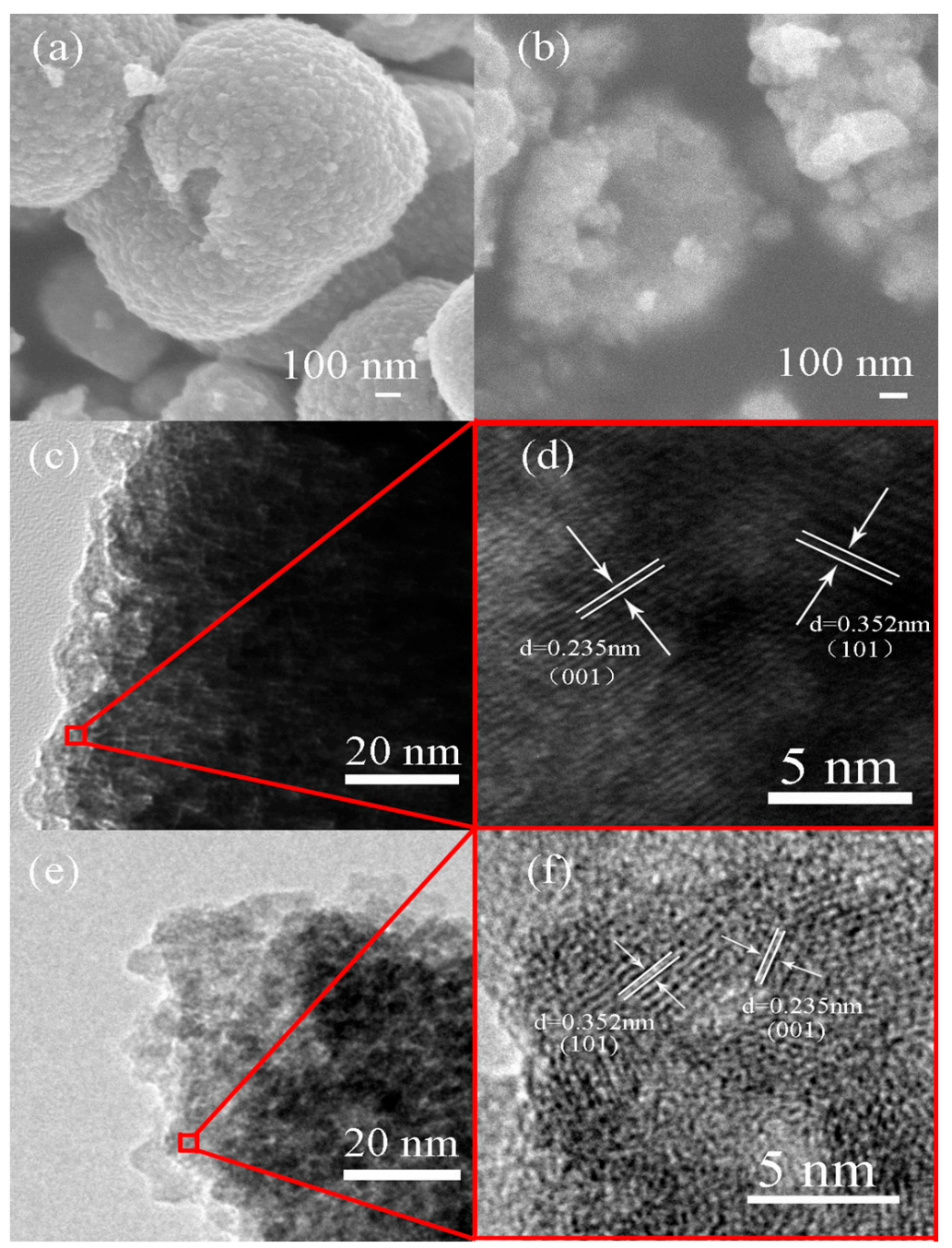

Figure 2. Field emission Scanning electron microscopy (FE-SEM) and high-resolution transmission electron microscope (HRTEM) of as-prepared $\mathrm{F}-\mathrm{TiO}_{2}$ and $\mathrm{OH}-\mathrm{TiO}_{2}$ samples. (a) FE-SEM images of $\mathrm{F}_{-T i O}$; (b) FE-SEM images of $\mathrm{OH}_{-} \mathrm{TiO}_{2} ;(\mathbf{c}, \mathbf{d}) \mathrm{HRTEM}$ images of $\mathrm{F}_{-} \mathrm{TiO}_{2} ;(\mathbf{e}, \mathbf{f}) \mathrm{HRTEM}$ images of $\mathrm{OH}-\mathrm{TiO}_{2}$.

Raman spectroscopy was used to calculate the percentage of (001) facets of the as-prepared catalysts (Figure 3). The percentage of (001) facets was calculated using the peak intensity ratio of the Eg and A1g peaks at $144 \mathrm{~cm}^{-1}$ and $514 \mathrm{~cm}^{-1}$, respectively [27,37]. The percentage of (001) facets for $\mathrm{F}-\mathrm{TiO}_{2}$ was $27.8 \%$, but after modification with $\mathrm{NaOH}$, the percentage of $\mathrm{OH}-\mathrm{TiO}_{2}$ increased to $39.2 \%$, which helped to enhance the photocatalytic performance of catalyst. 


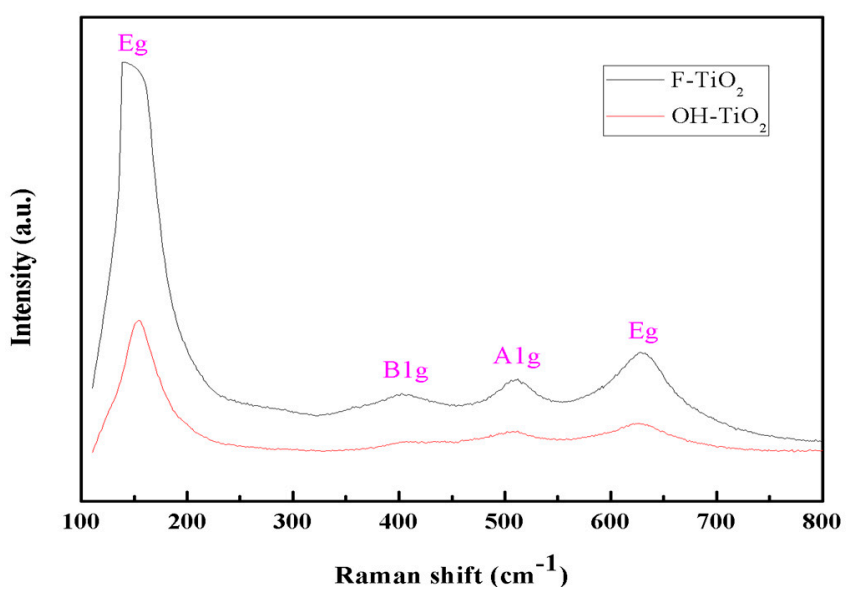

Figure 3. Raman spectroscopy of catalysts.

\subsection{UV-Vis DRS Analysis}

The UV-vis diffuse reflectance spectra (DRS) and bandgap of the as-prepared samples are shown in Figure 4. From Figure $4 \mathrm{a}$, the $\mathrm{F}_{-}-\mathrm{TiO}_{2}$ and $\mathrm{OH}-\mathrm{TiO}_{2}$ catalysts of are almost identical in terms of absorption between 230 and $550 \mathrm{~nm}$. In the range of 550 to $850 \mathrm{~nm}, \mathrm{OH}-\mathrm{TiO}_{2}$ has a light stronger absorption than $\mathrm{F}_{-} \mathrm{TiO}_{2}$, showing that $\mathrm{OH}-\mathrm{TiO}_{2}$ exhibits stronger light absorption ability in the visible light range. From Figure $4 \mathrm{~b}$, the $\mathrm{OH}-\mathrm{TiO}_{2}$ bandgap is $3.09 \mathrm{eV}$, which is somewhat smaller than that of $\mathrm{F}^{-\mathrm{TiO}_{2}}(3.17 \mathrm{eV})$. This may be attributed to the nest-like microstructure morphology of $\mathrm{OH}-\mathrm{TiO}_{2}$, which may promote light-scattering inside the pores of the shell wall and enhance absorption in light [25].

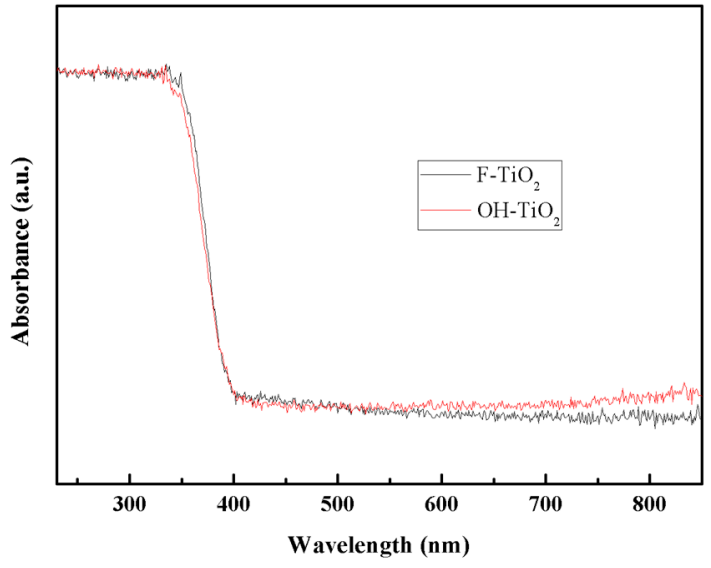

(a)

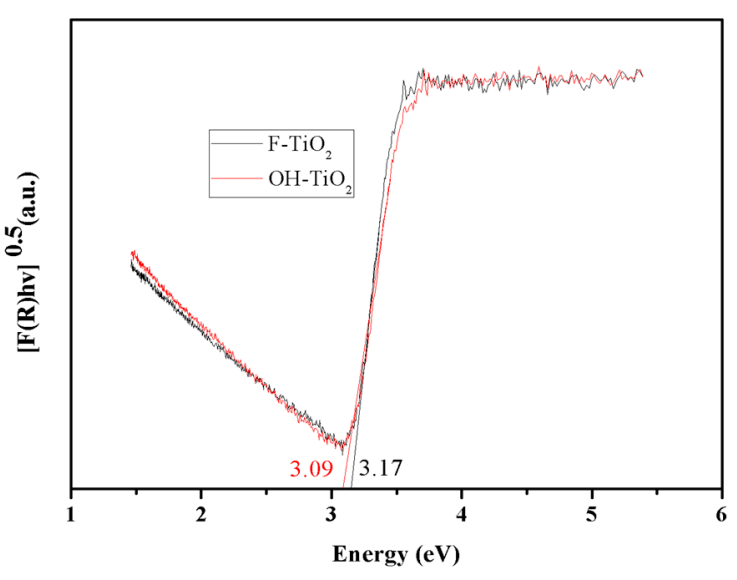

(b)

Figure 4. (a) UV-Vis diffuse reflectance spectra and (b) bandgap of as-prepared $\mathrm{F}-\mathrm{TiO}_{2}$ and $\mathrm{OH}-\mathrm{TiO}_{2}$ samples.

\subsection{FT-IR Analysis}

The Fourier transform infrared (FT-IR) spectroscopy was employed to investigate the chemical bonding of the catalysts (Figure 5a). The absorption peaks of $\mathrm{F}^{-\mathrm{TiO}_{2}}$ and $\mathrm{OH}-\mathrm{TiO}_{2}$ were observed at $3416 \mathrm{~cm}^{-1}$ and $1630 \mathrm{~cm}^{-1}$, respectively, which could be assigned to the adsorbed and bound $\mathrm{H}_{2} \mathrm{O}$ on the particles, respectively [38-40]. The span between 2934 and $3416 \mathrm{~cm}^{-1}$ is attributed to the $\mathrm{O}-\mathrm{H}$ bonds or associated $\mathrm{O}-\mathrm{H}$. O-H bonds appeared both in $\mathrm{F}_{-}-\mathrm{TiO}_{2}$ and $\mathrm{OH}-\mathrm{TiO}_{2}[39,40]$. The peaks around $672 \mathrm{~cm}^{-1}$ correspond to the characteristic absorption of Ti-O [29]. The peaks around $930 \mathrm{~cm}^{-1}$ are attributed to $\mathrm{F}-\mathrm{Ti}$ which disappeared after $\mathrm{NaOH}$ washing, meaning $\mathrm{F}$ was exchanged by $\mathrm{OH}$. 


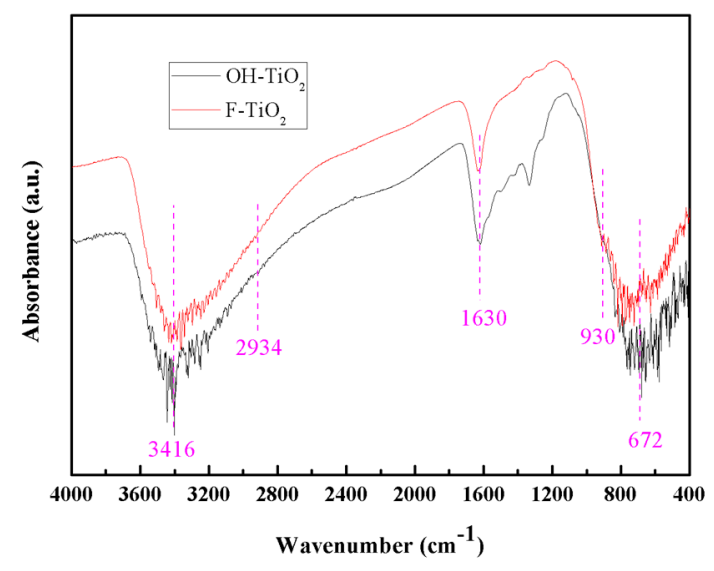

(a)

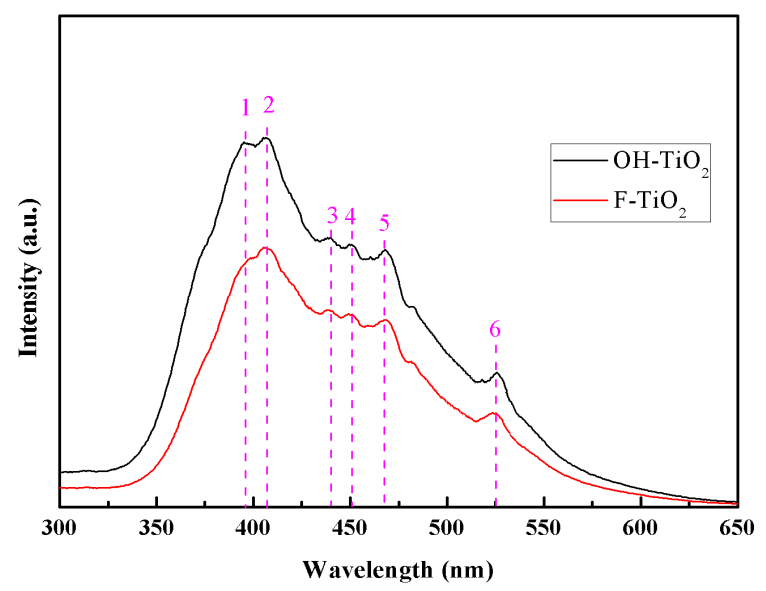

(b)

Figure 5. (a) Fourier transform infrared (FT-IR) spectra and (b) Photoluminescence (PL) emission spectra of as-prepared $\mathrm{F}-\mathrm{TiO}_{2}$ and $\mathrm{OH}-\mathrm{TiO}_{2}$ samples.

\subsection{Photoluminescence Analysis}

The Photoluminescence (PL) emission spectra were used to investigate the efficiency of charge carrier trapping, immigration and transfer, and to understand the fate of electron hole pairs in catalysts (Figure 5b). Six peaks were observed in the spectra. The broad emission band centered at $396 \mathrm{~nm}$ (peak 1) and $407 \mathrm{~nm}$ (peak 2) is ascribed to bound exciton emission due to the trapping of free excitons by titanate groups near defects [41]. The long wavelength range, from 440 to $465 \mathrm{~nm}$ (peaks 3, 4 and 5), is attributed to the oxygen vacancy with two trapped electrons. Peak 6, at $525 \mathrm{~nm}$, is assigned to the oxygen vacancy as a result of the Franck-Condon principle and the polarizability of the lattice ions surrounding the vacancy or one trapped electron, i.e., with a $\mathrm{Ti}^{3+}$ or $\mathrm{F}^{+}$center [41]. $\mathrm{OH}-\mathrm{TiO}_{2}$ has more oxygen vacancies than $\mathrm{F}^{-\mathrm{TiO}_{2}}$. Oxygen vacancy sites are important for the formation of superoxide $\left(\mathrm{O}_{2} \cdot{ }^{-}\right)$and hydroxyl $(\cdot \mathrm{OH})$ radicals for photocatalytic degradation.

\subsection{Photocatalytic Activity}

In the present work, the photocatalytic activity of $\mathrm{F}-\mathrm{TiO}_{2}$ and $\mathrm{OH}-\mathrm{TiO}_{2}$ was evaluated by monitoring the degradation of methylene blue $(\mathrm{MB})$ and Rhodamine $\mathrm{B}(\mathrm{RhB})$ solution under simulated solar irradiation. The degradation performance of catalysts and the variation in the UV-vis absorption spectra of the MB solution exposed to different $\mathrm{TiO}_{2}$ samples are shown in Figure 6. From Figure 6a, after modification with $\mathrm{NaOH}$, the degradation performance of $\mathrm{TiO}_{2}$ was considerably enhanced, especially for MB. The performance was almost the same as or better than $\mathrm{TiO}_{2}$ samples synthesized under high temperature or samples having other morphology [14,42]. In Figure $6 \mathrm{~b}$, from the line of no light, $20 \mathrm{mg}, C / C_{0}$ almost no longer decreased after $0.5 \mathrm{~h}$, meaning that it is an adsorption process in this $0.5 \mathrm{~h}$, and the adsorption balance is reached after $0.5 \mathrm{~h}$. From the line representing no catalysts, we can see that light played little role on the discoloration. Therefore, we can conclude that with catalysts the discoloration process is adsorption process in dark for $0.5 \mathrm{~h}$, after that the discoloration process is a photocatalytic degradation.

Figure $6 \mathrm{c}, \mathrm{d}$ shows the UV-vis absorption spectral changes of the $\mathrm{MB}$ solution by $\mathrm{OH}-\mathrm{TiO}_{2}$ and $\mathrm{F}-\mathrm{TiO}_{2}$, respectively. According to previous research, two processes can cause the discoloration of MB: oxidative degradation and two-electron reduction to leuco-MB which can be detected by the UV-vis absorption at $256 \mathrm{~nm}[43,44]$. From Figure 6d, a blue-shift from 665 to $625 \mathrm{~nm}$ and an absorbent peak at $256 \mathrm{~nm}$ emerged in the spectral change of MB with irradiation on OH-S0.5. This means that reductive conversion to leuco-MB occurs in the degradation path of MB. 

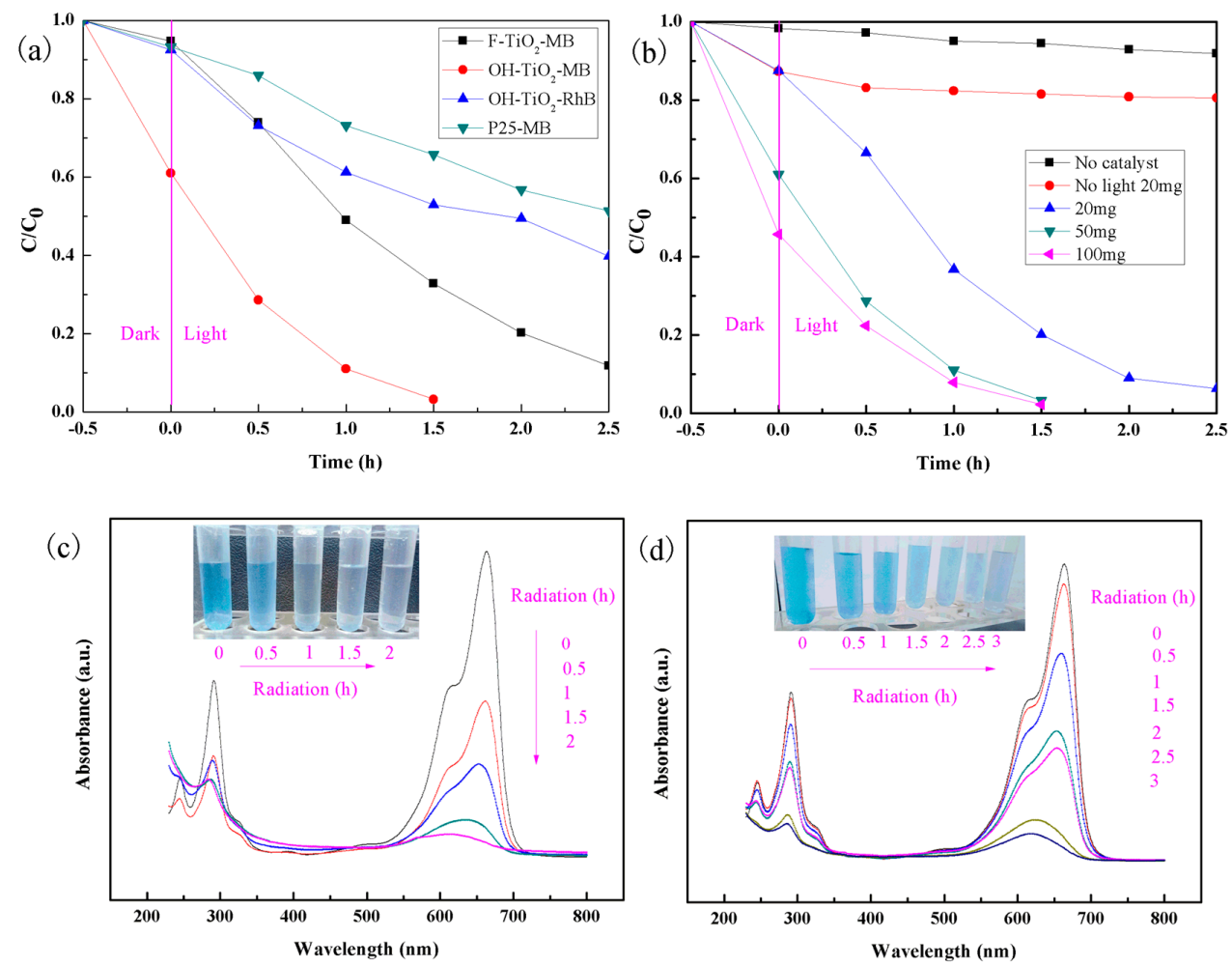

Figure 6. Photocatalytic performance of $\mathrm{OH}-\mathrm{TiO}_{2}$ and $\mathrm{F}-\mathrm{TiO}_{2}$ for $\mathrm{MB}$ and $\mathrm{RhB}$ and $\mathrm{UV}$-vis absorption spectral changes during the photocatalytic degradation of $\mathrm{MB}$ (a) photocatalytic performance of $\mathrm{MB}$ and $\mathrm{RhB}$ samples; (b) photocatalytic performance of $\mathrm{OH}-\mathrm{TiO}_{2}$ with varying amounts of catalysts; (c) UV-vis absorption spectral changes during the photocatalytic degradation of $\mathrm{MB}$ with $\mathrm{OH}-\mathrm{TiO}_{2}$; (d) UV-vis absorption spectral changes during the photocatalytic degradation of $\mathrm{MB}$ with $\mathrm{F}-\mathrm{TiO}_{2}$.

\subsection{Radical-Scavenging Experiments}

Radical-scavenging experiments were performed to complete an in-depth study of the photocatalytic degradation mechanism (Figure 7). Terephthalic acid can combine with the hydroxyl radicals $(\cdot \mathrm{OH})$ to reduce the activity of the catalyst, and the benzoquinone can combine with the superoxide radical $\left(\mathrm{O}_{2} \cdot{ }^{-}\right)$to decrease the activity of the catalyst. When terephthalic acid was added to the degradation system, the efficiency decreased more than with benzoquinone when benzoquinone was added, demonstrating that the hydroxyl radicals play a leading role in photocatalysis.

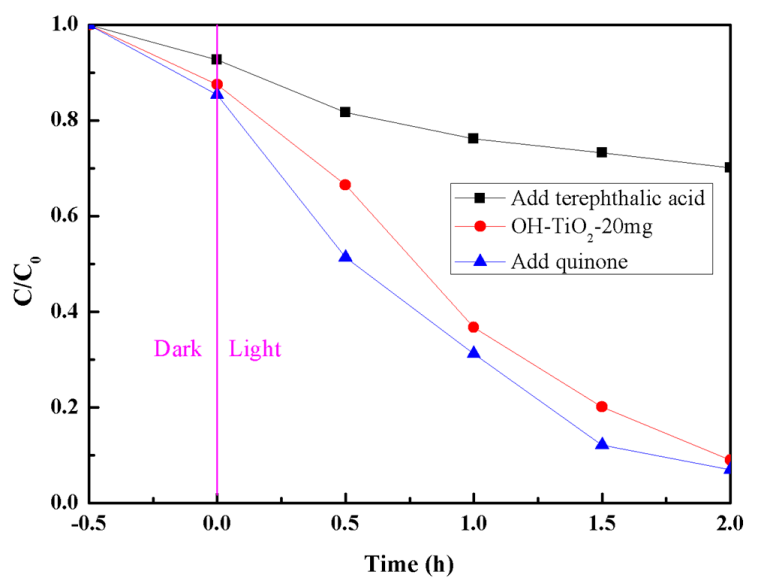

Figure 7. Radical-scavenging experiments of $\mathrm{OH}-\mathrm{TiO}_{2}$ and $\mathrm{F}-\mathrm{TiO}_{2}$ toward $\mathrm{MB}$. 


\section{Materials and Methods}

\subsection{Materials}

Tetrabutyl titanate, hydrofluoric acid, methylene blue, and benzoquinone (AR, KeLong Co., Ltd., Chengdu, China), anhydrous ethanol (AR, ChuanDong Co., Ltd., Chongqing, China), sodium hydroxide (AR, Kermel Co., Ltd., Tianjin, China), Rhodamine B (AR, FuChen Co., Ltd., Tianjin, China), barium sulfate (AR, XiLong Co., Ltd., Chengdu, China), and terephthalic acid (AR, Shanghai Macklin Biochemical Co., Ltd., Shanghai, China) were used for the experiments.

\subsection{Preparation of Catalysts}

A total of $15.20 \mathrm{~mL}$ anhydrous ethanol was added to $17.60 \mathrm{~mL}$ tetrabutyl titanate, denoted as solution $\mathrm{A}$; then $15.20 \mathrm{~mL}$ anhydrous ethanol was added to $90 \mathrm{~mL}$ ultra-pure water, with $6 \mathrm{~mL}$ $\mathrm{HF}$, recorded as solution B; solution A was added dropwise into solution B with a dropping speed of 2-3 drops per second and mixed at a low speed for $2 \mathrm{~h}$, the obtained titanium dioxide gel was stored at room temperature for two days. The aged $\mathrm{TiO}_{2}$ gel was moved to a stainless-steel reactor containing polytetrafluoroethylene, and kept at constant temperature of $100{ }^{\circ} \mathrm{C}$ for $2 \mathrm{~h}$. After cooling, the as-prepared power was washed with deionized water and ethanol 3 times and dried in a $100^{\circ} \mathrm{C}$ drying oven. After grinding, white powder was obtained, which was $\mathrm{F}-\mathrm{TiO}_{2}$.

Half of the above $\mathrm{F}^{-\mathrm{TiO}_{2}}$ powder was mixed with $10 \mathrm{~g} \mathrm{NaOH}$ and added to $100 \mathrm{~mL}$ distilled water, and stirred at medium speed for $2 \mathrm{~h}$, then centrifugally settled, washed 3 times with deionized water, dried in a $100{ }^{\circ} \mathrm{C}$ drying oven, and grinded to obtain the $\mathrm{OH}-\mathrm{TiO}_{2}$ samples.

\subsection{Catalyst Characterization}

The crystal structure of the powders were analyzed by X-ray diffractometry (XRD) (Bruker, D8-Advance, Rheinstetten, Germany) with $\mathrm{Cu} \mathrm{K} \alpha$ radiation ( $\lambda=0.154 \mathrm{~nm}, 40 \mathrm{kV}, 40 \mathrm{~mA}$ ) with a scanning range of $20^{\circ}$ to $80^{\circ}$. The UV-Vis absorption spectra of the powders were obtained from dry-pressed disk samples with a UV-Vis spectrometer (TU-1911, Shanghai, China), $\mathrm{BaSO}_{4}$ was used as a reflectance standard in the UV-Vis diffuse reflectance. The microstructure of the powers were examined by field-emission scanning (FE-SEM) (JEOL, JSM-6700F, Tokyo, Japan) operating at $5.0 \mathrm{KV}$ and transmission electron microscopy and high resolution transmission electron microscopy (HRTEM) (Tecnai G2 F20, FEI, Hillsboro, OR, USA), using a $200 \mathrm{kV}$ accelerating voltage. Fourier transform infrared (FT-IR) spectra were analyzed (Bruker, Tensor27, Rheinstetten, Germany) in the wavenumber range from 4000 to $400 \mathrm{~cm}^{-1}$. The Photoluminescence (PL) emission spectra were measured at room temperature with a fluorescence spectrophotometer (Hitachi F-2700, Tokyo, Japan) using $325 \mathrm{~nm}$ line with a Xe lamp.

\subsection{Photocatalytic Activity Tests}

The photocatalytic activities of both samples were evaluated by the degradation of methylene blue (MB) and Rhodamine B (RhB) solution under simulated solar light. The photocatalytic degradation tests were performed in an $200 \mathrm{~mL}$ double-layered quartz glass reactor With either $100 \mathrm{~mL} 10 \mathrm{mg} / \mathrm{L}$ $\mathrm{MB}$ or $\mathrm{RhB}$ and certain quantities of catalysts. Cooling water was introduced into the interlayer of the quartz reactor to maintain the solution at room temperature. A Jiguang-300W Xe lamp (simulating solar light) was located $30 \mathrm{~cm}$ away from the $\mathrm{MB}$ or $\mathrm{RhB}$ solution. When the solution was magnetically stirred for $0.5 \mathrm{~h}$ in dark to obtain the adsorption-desorption equilibrium, the Xe lamp was turned on to initiate the degradation. About $4.0 \mathrm{~mL}$ of solution was extracted and centrifuged at a speed of $11,000 \mathrm{r} / \mathrm{min}$ to remove catalysts every $0.5 \mathrm{~h}$. Then, the MB or RhB concentration were analyzed on a Purkinje UV1901 UV-vis spectrophotometer at $665 \mathrm{~nm}$ or $554 \mathrm{~nm}$. The photocatalyst was separated from the $\mathrm{MB}$ or RhB solution and another run was started to investigate the catalysts durability. Because the absorbance of simulated azo dye wastewater has a linear relationship with the concentration of 
dye contained therein, the degradation of dyes is indirectly reflected by measuring the absorbance change of simulated dye wastewater.

The photocatalytic reaction efficiency $(100 \%)=A / A_{0} \times 100 \%=C / C_{0} \times 100 \%$.

Where $A_{0}$ is the absorbance before the reaction, and $A$ is the absorbance of every $0.5 \mathrm{~h}$ centrifuge in the reaction; $C_{0}$ is the absorbance before the reaction, and $C$ is the absorbance obtained by every $0.5 \mathrm{~h}$ centrifuge in the reaction.

Terephthalic acid $(3 \mathrm{mmol} / \mathrm{L})$ and p-benzoquinone were added to a mixed solution containing $20 \mathrm{mg}$ of $\mathrm{OH}-\mathrm{TiO}_{2}$ and $100 \mathrm{~mL}$ of $10 \mathrm{mg} / \mathrm{L}$ of methylene blue solution, and methylene blue was degraded as a control.

\section{Conclusions}

A simple low-temperature synthesis of nest-like $\mathrm{TiO}_{2}$ microspheres with exposed (001) facets was reported and its photocatalytic performance was enhanced by $\mathrm{NaOH}$ alkalization for the first time in this study. The photocatalytic activity of the as-prepared catalyst was evaluated by photocatalytic degradation of methylene blue and Rhodamine B under simulated solar light. The results show that the $\mathrm{NaOH}$ alkalized microspheres had superior catalytic photoactivity compared to (001) $\mathrm{TiO}_{2}$ towards MB. The reason for this result may be related to its unique nest-like morphology, increased (001) facet exposure, more $\mathrm{O}-\mathrm{H}$, and more oxygen vacancy sites. Radical-scavenging experiments revealed that the hydroxyl radicals play a leading role in photocatalysis.

Acknowledgments: Financial support was provided by Shaanxi key industrial projects (2014GY2-07) and Shaanxi Province education department science and technology research plan (15JK1460).

Author Contributions: In this paper, Chentao Hou and Jiaming Zhu designed the experiments; Jiaming Zhu and Qiaoqiao Song conducted the experiments; Chentao Hou and Jiaming Zhu analyzed the data; Chentao Hou wrote the article.

Conflicts of Interest: No conflict of interest exists in this manuscript submission, and it has been approved by all of the authors for publication. All authors listed have approved the manuscript enclosed.

\section{References}

1. Fujishima, A.; Honda, K. Electrochemical photolysis of water at a semiconductor electrode. Nature 1972, 238, 37-38. [CrossRef] [PubMed]

2. Tian, F.; Wu, Z.; Chen, Q.; Yan, Y.; Cravotto, G.; Wu, Z. Microwave-induced crystallization of $\mathrm{AC} / \mathrm{TiO}_{2}$ for improving the perfomnance of rhodamine B dye degradation. Appl. Surf. Sci. 2015, 351, 104-112. [CrossRef]

3. Atout, H.; Álvarez, M.G.; Chebli, D.; Bouguettoucha, A.; Tichit, D.; Llorca, J.; Medina, F. Enhanced photocatalytic degradation of methylene blue: Preparation of $\mathrm{TiO}_{2} /$ reduced graphene oxide nanocomposites by direct sol-gel and hydrothermal methods. Mater. Res. Bull. 2017, 50, 952-957. [CrossRef]

4. Zhang, S.T.; Ruan, Y.R.; Liu, C.; Wang, P.; Ma, Y.Q. The evolution of structure, chemical state and photocatalytic performance of $\alpha-\mathrm{Fe} / \mathrm{FeTiO}_{3} / \mathrm{TiO}_{2}$ with the nitridation at different temperatures. Mater. Res. Bull. 2017, 95, 503-508. [CrossRef]

5. Bessegato, G.G.; Guaraldo, T.T.; Brito, J.F.; Brugnera, M.F. Achievements and trends in photoelectrocatalysis: From environmental to energy applications. Electrocatalysis 2015, 6, 415-441. [CrossRef]

6. Michele, L.; Andrea, V.; Annabella, S. Structure and energetics of stoichiometric $\mathrm{TiO}_{2}$ anatase surfaces. Phys. Rev. B 2001, 65, 155409. [CrossRef]

7. Minero, C.; Mariella, G.; Maurino, V.; Vione, D.; Pelizzetti, E. Photocatalytic transformation of organic compounds in the presence of inorganic ions Competitive reactions of phenol and alcohols on a titanium dioxide-fluoride system. Langmuir 2000, 16, 8964-8972. [CrossRef]

8. Huang, W.C.; Ting, J.-M. Novel nitrogen-doped anatase $\mathrm{TiO}_{2}$ mesoporous bead photocatalysts for enhanced visible light response. Ceram. Int. 2017, 43, 9992-9997. [CrossRef]

9. Khalid, N.R.; Majid, A.; Tahir, M.B.; Niaz, N.A.; Khalid, S. Carbonaceous-TiO ${ }_{2}$ nanomaterials for photocatalytic degradation of pollutants: A review. Ceram. Int. 2017, 43, 14552-14571. [CrossRef] 
10. Gjipalaj, J.; Alessandri, I. Easy recovery; mechanical stability; enhanced adsorption capacity and recyclability of alginate-based $\mathrm{TiO}_{2}$ macrobead photocatalysts for water treatment. J. Environ. Chem. Eng. 2017, 5, 1763-1770. [CrossRef]

11. Chowdhury, I.H.; Ghosh, S.; Basak, S.; Naskar, M.K. Mesoporous CuO-TiO 2 microspheres for efficient catalytic oxidation of CO and photodegradation of methylene blue. J. Phys. Chem. Solids 2017, 104, 103-110. [CrossRef]

12. Cao, X.; Luo, S.; Liu, C.; Chen, J. Synthesis of Bentonite-Supported $\mathrm{Fe}_{2} \mathrm{O}_{3}$-Doped $\mathrm{TiO}_{2}$ superstructures for highly promoted photocatalytic activity and recyclability. Adv. Powder Technol. 2017, 28, 993-999. [CrossRef]

13. Liu, S.; Yu, J.; Jaroniec, M. Tunable Photocatalytic Selectivity of Hollow $\mathrm{TiO}_{2}$ Microspheres Composed of Anatase Polyhedra with Exposed $\{001\}$ Facets. J. Am. Chem. Soc. 2010, 132, 11914-11916. [CrossRef] [PubMed]

14. Zhao, J.; Li, W.; Li, X.; Zhang, X. Low temperature synthesis of water dispersible F-doped $\mathrm{TiO}_{2}$ nanorods with enhanced photocatalytic activity. RSC Adv. 2017, 7, 21547-21555. [CrossRef]

15. Zhu, Z.F.; Zhou, J.Q.; He, Z.L.; Li, J.Q.; Liu, H. Preparation, characterisation and activity of $\mathrm{TiO}_{2-x} \mathrm{~F}_{\mathrm{x}}$ spherical photocatalyst: Influence of sodium fluoride on methyl orange degradation. Mater. Res. Innov. 2011, 15, 78-82. [CrossRef]

16. Wang, Q.; Chen, C.; Zhao, D.; Ma, W.; Zhao, J. Change of Adsorption Modes of Dyes on Fluorinated $\mathrm{TiO}_{2}$ and Its Effect on Photocatalytic Degradation of Dyes under Visible Irradiation. Langmuir 2008, 24, 7338-7345. [CrossRef] [PubMed]

17. Yu, J.C.; Ho, W.K.; Yu, J.G.; Hark, S.K.; Iu, K. Effects of trifluoroacetic acid modification on the surface microstructures and photocatalytic activity of mesoporous $\mathrm{TiO}_{2}$ thin films. Langmuir 2003, 19, 3889-3896. [CrossRef]

18. Lewandowski, M.; Ollis, D.F. Halide acid pretreatments of photocatalysts for oxidation of aromatic air contaminants: rate enhancement, rate inhibition and a thermodynamic rationale. Catalysis 2003, 217, $38-46$. [CrossRef]

19. Yang, H.G.; Sun, C.H.; Qiao, S.Z.; Zou, J.; Liu, G.; Smith, S.C.; Cheng, H.M.; Lu, G.Q. Anatase TiO 2 single crystals with a large percentage of reactive facets. Nature 2008, 453, 638-641. [CrossRef] [PubMed]

20. Peng, J.-D.; Lin, H.-H.; Lee, C.-T.; Tseng, C.-M.; Suryanarayanan, V.; Vittala, R.; Ho, K.-C. Hierarchically assembled microspheres consisting of nanosheets of highly exposed (001)-facets $\mathrm{TiO}_{2}$ for dye-sensitized solar cells. RSC Adv. 2016, 6, 14178-14191. [CrossRef]

21. Tian, F.; Zhang, Y.; Zhang, J.; Pan, C. Raman Spectroscopy: A New Approach to Measure the Percentage of Anatase $\mathrm{TiO}_{2}$ Exposed (001) Facets. J. Phys. Chem. C 2012, 116, 7515-7519. [CrossRef]

22. He, Z.; Wen, L.; Wang, D.; Xue, Y.; Lu, Q.; Wu, C.; Chen, J.; Song, S. Photocatalytic Reduction of $\mathrm{CO}_{2}$ in Aqueous Solution on Surface-Fluorinated Anatase $\mathrm{TiO}_{2}$ Nanosheets with Exposed $\{001\}$ Facets. Energy Fuels 2014, 28, 3982-3993. [CrossRef]

23. He, Z.; Cai, Q.; Hong, F.; Jiang, Z.; Chen, J.; Song, S. Effective Enhancement of the Degradation of Oxalic Acid by Catalytic Ozonation with $\mathrm{TiO}_{2}$ by Exposure of $\{001\}$ Facets and Surface Fluorination. Ind. Eng. Chem. Res. 2012, 51, 5662-5668. [CrossRef]

24. Nguyen, V.-H.; Lasek, J.; Jeffrey, C.S.; Yu, J.C.-C. Titania nanosheet photocatalysts with dominantly exposed (001) reactive facets for photocatalytic $\mathrm{NO}_{x}$ abatement. Appl. Catal. B Environ. 2017, 219, 391-400. [CrossRef]

25. Zhang, G.; Zhang, S.; Wang, L.; Liu, R.; Zeng, Y.; Xia, X.; Liu, Y.; Luo, S. Facile synthesis of bird's nest-like TiO 2 microstructure with exposed (001) facets for photocatalytic degradation of methylene blue. Appl. Surf. Sci. 2017, 391, 228-235. [CrossRef]

26. Zhang, Y.; Xia, T.; Shang, M.; Wallenmeyer, P.; Katelyn, D.; Peterson, A.; Murowchick, J.; Dong, L.; Chen, X. Structural evolution from $\mathrm{TiO}_{2}$ nanoparticles to nanosheets and their photocatalytic performance in hydrogen generation and environmental pollution removal. RSC Adv. 2014, 4, 16146-16152. [CrossRef]

27. Chu, L.; Qin, Z.; Yang, J.; Li, X. Anatase $\mathrm{TiO}_{2}$ Nanoparticles with Exposed $\{001\}$ Facets for Efficient Dye-Sensitized Solar Cells. Sci. Rep. 2015, 5, 12143. [CrossRef] [PubMed]

28. Han, D.; Zhou, C.; Yin, H.; Zhang, D.; Xu, X. Reactivity of the alkaline pretreated nanoporous gold for the CO oxidation. Catal. Lett. 2011, 141, 1026-1031. [CrossRef]

29. Gopalakrishnan, S.; Zampieri, A.; Schwieger, W. Mesoporous ZSM-5 zeolites via alkali treatment for the direct hydroxylation of benzene to phenol with $\mathrm{N}_{2}$ O. J. Catal. 2008, 260, 193-197. [CrossRef] 
30. Su, L.L.; Zhang, J.Q.; Wang, H.X.; Li, Y.G.; Shen, W.J.; Xu, Y.D.; Bao, X.H. Creating mesopores in ZSM-5 zeolite by alkali treatment: A new way to enhance the catalytic performance of methane dehydroaromatization on Mo/HZSM-5 catalysts. Catal. Lett. 2003, 91, 155-167. [CrossRef]

31. Xiang, Q.J.; Lv, K.L.; Yu, J.G. Pivotal role of fluorine in enhanced photocatalytic activity of anatase $\mathrm{TiO}_{2}$ nanosheets with dominant (001) facets for the photocatalytic degradation of acetone in air. Appl. Catal. B Environ. 2010, 96, 557-564. [CrossRef]

32. Hou, C.; Liu, W.; Zhu, J. Synthesis of NaOH-Modified $\mathrm{TiOF}_{2}$ and Its Enhanced Visible Light Photocatalytic Performance on RhB. Catalysts 2017, 7, 243. [CrossRef]

33. Yang, H.G.; Zeng, H.C. Preparation of hollow anatase $\mathrm{TiO}_{2}$ nanospheres via Ostwald ripening. Phys. Chem. B 2004, 108, 3492-3495. [CrossRef]

34. Zhao, W.; Liu, N.; Wang, H.; Mao, L. Sacrificial template synthesis of coreshell $\mathrm{SrTiO}_{3} / \mathrm{TiO}_{2}$ heterostructured microspheres photocatalyst. Ceram. Int. 2017, 43, 4807-4813. [CrossRef]

35. Zo, M.; Liu, H.; Feng, L.; Xiong, F.; Thoma, T.; Yang, M. Effect of nitridation on visible light photocatalytic behavior of microporous ( $\mathrm{Ag}, \mathrm{Ag}_{2} \mathrm{O}$ ) co-loaded $\mathrm{TiO}_{2}$. Microporous Mesoporous Mater. 2017, 240, $137-144$. [CrossRef]

36. Guo, S.-Y.; Dai, J.-G.; Zhao, T.-J.; Hou, S.-D.; Zhang, P.; Wang, P.; Sun, G.-X. A novel microporous morphous-ZnO@ $\mathrm{TiO}_{2}$ /graphene ternary nanocomposite with enhanced photocatalytic activity. RSC Adv. 2017, 7, 36787-36792. [CrossRef]

37. Tayade, R.J.; Surolia, P.K.; Kulkarni, R.G.; Jasra, R.V. Photocatalytic degradation of dyes and organic contaminants in water using nanocrystalline anatase and rutile $\mathrm{TiO}_{2}$. Sci. Technol. Adv. Mater. 2007, 8, 455-462. [CrossRef]

38. Xu, S.H.; Shangguan, W.F.; Yuan, J. Synthesis and performance of novel magnetically separable nanospheres of titanium dioxide photocatalyst with egg-like structure. Nanotechnology 2008, 19. [CrossRef] [PubMed]

39. Iwata, T.; Watanabe, A.; Iseki, M.; Watanabe, M.; Kandor, H. Strong Donation of the Hydrogen Bond of Tyrosine during Photoactivation of the BLUF Domain. Phys. Chem. Lett. 2011, 2, 1015-1019. [CrossRef]

40. Ning, Y. Structural Identification of Organic Compounds and Organic Spectroscopy; Science Press: Beijing, China, 2000; ISBN 978-7-03-0074-126.

41. Li, D.; Haneda, H.; Hishita, S.; Ohashi, N. Visible-Light-Driven N-F-Codoped $\mathrm{TiO}_{2}$ Photocatalysts. 2. Optical Characterization, Photocatalysis, and Potential Application to Air Purification. Chem. Mater. 2005, 17, 2596-2602. [CrossRef]

42. Zhang, J.; Hou, X.; Pang, Z.; Cai, Y.; Zhou, H.; Lv, P.; Wei, Q. Fabrication of hierarchical $\mathrm{TiO}_{2}$ nanofibers by microemulsion electrospinning for photocatalysis applications. Ceram. Int. 2017, 43, 15911-15917. [CrossRef]

43. Hu, Y.; Li, D.; Zheng, Y.; Chen, W.; He, Y.; Shao, Y.; Fu, X.; Xiao, G. $\mathrm{BiVO}_{4} / \mathrm{TiO}_{2}$ nanocrystalline heterostructure: A wide spectrum responsive photocatalyst towards the highly efficient decomposition of gaseous benzene. Appl. Catal. B Environ. 2011, 104, 30-36. [CrossRef]

44. Park, H.; Choi, W. Photocatalytic Reactivities of Nafion-Coated $\mathrm{TiO}_{2}$ for the Degradation of Charged Organic Compounds under UV or Visible Light. J. Phys. Chem. B 2005, 109, 11667-11674. [CrossRef] [PubMed]

(C) 2018 by the authors. Licensee MDPI, Basel, Switzerland. This article is an open access article distributed under the terms and conditions of the Creative Commons Attribution (CC BY) license (http://creativecommons.org/licenses/by/4.0/). 